\title{
Comparison of End-Tidal, Arterial, Venous, and Transcutaneous $\mathrm{P}_{\mathrm{CO}_{2}}$
}

\author{
Shota Fujimoto, Manabu Suzuki, Keita Sakamoto, Ritsu Ibusuki, Kentaro Tamura, \\ Ayako Shiozawa, Satoru Ishii, Motoyasu Iikura, Shinyu Izumi, and Haruhito Sugiyama
}

\begin{abstract}
BACKGROUND: We investigated the measurement of end-tidal partial pressure of carbon dioxide $\left(\mathrm{P}_{\mathrm{ETCO}_{2}}\right)$ with a capnometer in patients with respiratory failure, and we determined whether this technique could provide an alternative to measurement of $\mathbf{P}_{\mathrm{aCO}}$ using arterial blood gas analysis in the clinical setting. METHODS: We measured $\mathbf{P}_{\mathrm{ETCO}_{2}}$ in subjects with hypoxemic and hypercarbic respiratory failure using a capnometer. We simultaneously measured $\mathrm{P}_{\mathrm{aCO}_{2}}$, venous partial pressure of carbon dioxide $\left(\mathbf{P}_{\overline{\mathrm{v}} \mathrm{CO}_{2}}\right)$, and transcutaneously measured partial pressure $\mathbf{P}_{\mathrm{CO}_{2}}\left(\mathbf{P}_{\mathrm{tcCO}_{2}}\right)$. We analyzed agreements among these parameters with Bland-Altman analysis. We obtained 30 samples from subjects with hypoxemic respiratory failure and $\mathbf{3 0}$ samples from subjects with hypercarbic respiratory failure. RESULTS: Thirty subjects with hypoxemic respiratory failure and 18 subjects with hypercarbic respiratory failure participated in this study. Significant relationships were found between $\mathrm{P}_{\mathrm{ETCO}_{2}}$ and $\mathrm{P}_{\mathrm{aCO}}$, between $\mathrm{P}_{\mathrm{tcCO}}$ and $\mathrm{P}_{\mathrm{aCO}}$, and between $\mathrm{P}_{\overline{\mathrm{v} C O}}$ and $\mathrm{P}_{\mathrm{aCO}} \cdot$ Bland-Altman analysis of $\mathrm{P}_{\mathrm{ETCO}_{2}}$ and $\mathrm{P}_{\mathrm{aCO}}$ in all subjects revealed a bias of $6.48 \mathrm{~mm} \mathrm{Hg} \mathrm{(95 \%} \mathrm{CI} \mathrm{4.93-8.03,}$ $P<.001$ ) with a precision of $6.01 \mathrm{~mm} \mathrm{Hg}$. Bland-Altman analysis of $\mathbf{P}_{\mathrm{ETCO}_{2}}$ and $\mathbf{P}_{\mathrm{aCO}}$ with hypoxemic respiratory failure revealed a bias of $5.14 \mathrm{~mm} \mathrm{Hg}(95 \%$ CI $3.35-6.93, P<.001)$ with a precision of $4.80 \mathrm{~mm} \mathrm{Hg}$. Bland-Altman analysis of $\mathrm{P}_{\mathrm{ETCO}}$ and $\mathrm{P}_{\mathrm{aCO}}$ in subjects with hypercarbic respiratory failure revealed a bias of $7.83 \mathrm{~mm} \mathrm{Hg}(95 \% \mathrm{CI} 5.27-10.38, P<.001)$ with a precision of $6.83 \mathrm{~mm} \mathrm{Hg}$. CONCLUSIONS: $P_{\mathrm{ETCO}_{2}}$ can be measured simply using a capnometer, and $\mathbf{P}_{\mathrm{ETCO}_{2}}$ measurements can estimate $\mathbf{P a C O}_{2}$. However, the limits of agreement were wide. Therefore, care providers must pay attention to the characteristics and errors of these devices. These results suggest that measurement of $\mathbf{P}_{\mathbf{E T C O}}$ might be useful for screening for hypercarbic respiratory failure in the clinical setting. Key words: capnography; COPD; hypercapnia; monitoring; primary healthcare; respiratory failure. [Respir Care 2019;64(10):1208-1214. (C) 2019 Daedalus Enterprises]
\end{abstract}

\section{Introduction}

Hypoxemic respiratory failure is a respiratory disorder in which patients have a $\mathrm{P}_{a O_{2}}$ in room air of $\leq 60 \mathrm{~mm} \mathrm{Hg}$ and a $\mathrm{P}_{\mathrm{aCO}_{2}}<45 \mathrm{~mm} \mathrm{Hg}$ due to respiratory dysfunction. In contrast, a $\mathrm{P}_{\mathrm{aCO}_{2}}$ of $>45 \mathrm{~mm} \mathrm{Hg}$ is defined as hypercarbic respiratory failure. Evaluation of hypercapnia and

The authors are affiliated with the Department of Respiratory Medicine, National Center for Global Health and Medicine, Tokyo, Japan.

Dr Fujimoto presented the results at the 2017 Congress of the Asian Pacific Society of Respirology, held November 23-26, 2017, in Sydney, Australia.

Air Water Medical provided the CapnoEye MC-600 device free of charge. The authors have disclosed no conflicts of interest. hypoxemia is essential when treating patients with respiratory disease, especially patients with hypercapnic respiratory failure. Arterial blood sampling is therefore required, sometimes repeatedly, but ideally noninvasive techniques should be used when possible to monitor the patient's respiratory condition in the hospital, as well as in outpatient clinics. ${ }^{1}$ Oxygen saturation is thus commonly measured because pulse oximetry offers a simple and noninvasive approach.

Correspondence: Manabu Suzuki MD, Department of Respiratory Medicine, National Center for Global Health and Medicine, 1-21-1 Toyama Shinjuku-ku, Tokyo 162-8655, Japan. E-mail: manabu@nms.ac.jp.

DOI: $10.4187 /$ respcare.06094 
Measurement of end-tidal partial pressure of carbon dioxide $\left(\mathrm{P}_{\mathrm{ETCO}_{2}}\right)$ also provides a noninvasive method for estimating $\mathrm{P}_{\mathrm{aCO}}$; however, it is difficult to collect pure respiratory gas in patients who are not intubated, making it difficult to measure $\mathrm{P}_{\mathrm{ETCO}}$ accurately. We previously measured $\mathrm{P}_{\mathrm{ETCO}_{2}}$ by attaching a monitor to the ventilator circuit, and measurement of $\mathrm{P}_{\mathrm{ETCO}_{2}}$ has therefore usually been limited to patients in settings such as the operating room and ICU. ${ }^{2}$ It is unknown whether measurement of $\mathrm{P}_{\mathrm{ETCO}_{2}}$ using a capnometer in spontaneously breathing patients can be used as an alternative measurement of $\mathrm{P}_{\mathrm{aCO}_{2}}$ to using arterial blood gas analysis in the clinical setting. We therefore evaluated $\mathrm{P}_{\mathrm{ETCO}_{2}}$ measured with a capnometer and $\mathrm{P}_{\mathrm{aCO}}$ in subjects with hypoxemic and hypercarbic respiratory failure and calculated their agreement and accuracy. We also compared these characteristics for transcutaneously measured partial pressure of carbon dioxide $\left(\mathrm{P}_{\mathrm{tcCO}_{2}}\right)$, which is covered by insurance in Japan, and venous partial pressure of carbon dioxide $\left(\mathrm{P}_{\overline{\mathrm{v}} \mathrm{CO}_{2}}\right)$ against $\mathrm{P}_{\mathrm{aCO}_{2}}$.

\section{Methods}

\section{Ethical Consideration}

This was a prospective observational cohort study of subjects who received out-patient care or were admitted to the National Center for Global Health and Medicine between February 2017 and April 2017. All subjects provided informed consent for inclusion before participation in the study. The study was conducted in accordance with the Declaration of Helsinki, and the protocol was approved by the Ethics Committee of Clinical Investigation for the National Center for Global Health and Medicine (Approval Number: NCGM-G-002135-00).

\section{Equipment}

$\mathrm{P}_{\mathrm{ETCO}_{2}}$ was measured using a CapnoEye MC-600 (Air Water Medical, Tokyo, Japan). This is a transportable mainstream pulse oxi-capnometer that enables measurement of $\mathrm{P}_{\mathrm{ETCO}_{2}}$ and oxygen saturation by pulse oximetry at the patient's bedside, either in the hospital or at the patient's home (Fig. 1A, 1B). Measurements were performed using a mouthpiece from a conventional capnometer, but with the device's own analysis algorithm. Subjects held the mouthpiece in their mouth and breathed quietly 6 times. $\mathrm{P}_{\mathrm{ETCO}_{2}}$ measurements were based on a nondispersive infrared absorption method, which utilizes the ability to absorb infrared light of a wavelength corresponding to the concentration of carbon dioxide contained in the expired gas. Infrared light is irradiated toward and absorbed by the respiratory gas, and the amount of remaining light is detected by a light receiver through 2 types of optical filters.

\section{QUICK LOOK}

\section{Current knowledge}

Evaluation of hypercapnia and hypoxemia is essential when treating patients with respiratory disease, especially in patients with hypercapnic respiratory failure. It is preferable to use the most noninvasive monitoring technique possible to monitor the patient's respiratory condition.

\section{What this paper contributes to our knowledge}

$\mathrm{P}_{\mathrm{ETCO}_{2}}$ can be measured simply using a capnometer. Measurement of $\mathrm{PETCO}_{2}$ in spontaneously breathing patients might be useful for screening for hypercapnic respiratory failure. However, clinicians must be aware of the characteristics and potential errors of these devices.

The $\mathrm{P}_{\mathrm{ETCO}_{2}}$ level was then obtained based on the measured value.

$\mathrm{P}_{\mathrm{tcCO}_{2}}$ was measured with a TCM TOSCA device (Radiometer Basel AG, Basel, Switzerland) (Fig. 1C), which is an established method for obtaining $\mathrm{P}_{\mathrm{tcCO}_{2}}$. Several reports have described its use as a monitor, ${ }^{3}$ and it has demonstrated good correlation between $\mathrm{P}_{\mathrm{aCO}}$ and $\mathrm{P}_{\mathrm{tcCO}}$ when used in the operating room. ${ }^{4}$ The device was calibrated beforehand using carbon dioxide gas built into the TCM TOSCA. The probe was then attached to the earlobe using a dedicated clip, and $\mathrm{P}_{\mathrm{tcCO}_{2}}$ was recorded after the value measured by the TCM TOSCA had stabilized.

Arterial blood samples were drawn from either the right or left radial artery and collected via a heparinized needle and syringe system. Venous blood samples were drawn from either the right or left antecubital vein and aspirated into a separate heparinized blood gas syringe via a needle. The samples were analyzed using a blood gas analyzer (GASTAT 602i; Techno Medica, Yokohama, Japan) as quickly as possible after collection.

\section{Subjects and Study Design}

We screened and registered subjects already known to satisfy the definitions of respiratory failure regarding $\mathrm{P}_{\mathrm{aO}_{2}}$ measures prior to being placed on supplemental oxygen. We simultaneously measured $\mathrm{P}_{\mathrm{ETCO}_{2}}, \mathrm{P}_{\mathrm{aCO}_{2}}, \mathrm{P}_{\overline{\mathrm{v}} \mathrm{CO}_{2}}$, and $\mathrm{P}_{\mathrm{tcCO}_{2}}$, and we then analyzed the relationships among these parameters and compared the measured data between the 2 groups.

Measurements were performed while the subjects rested in a sitting position. A constant oxygen dose was administered during the measurement period, but this was inter- 

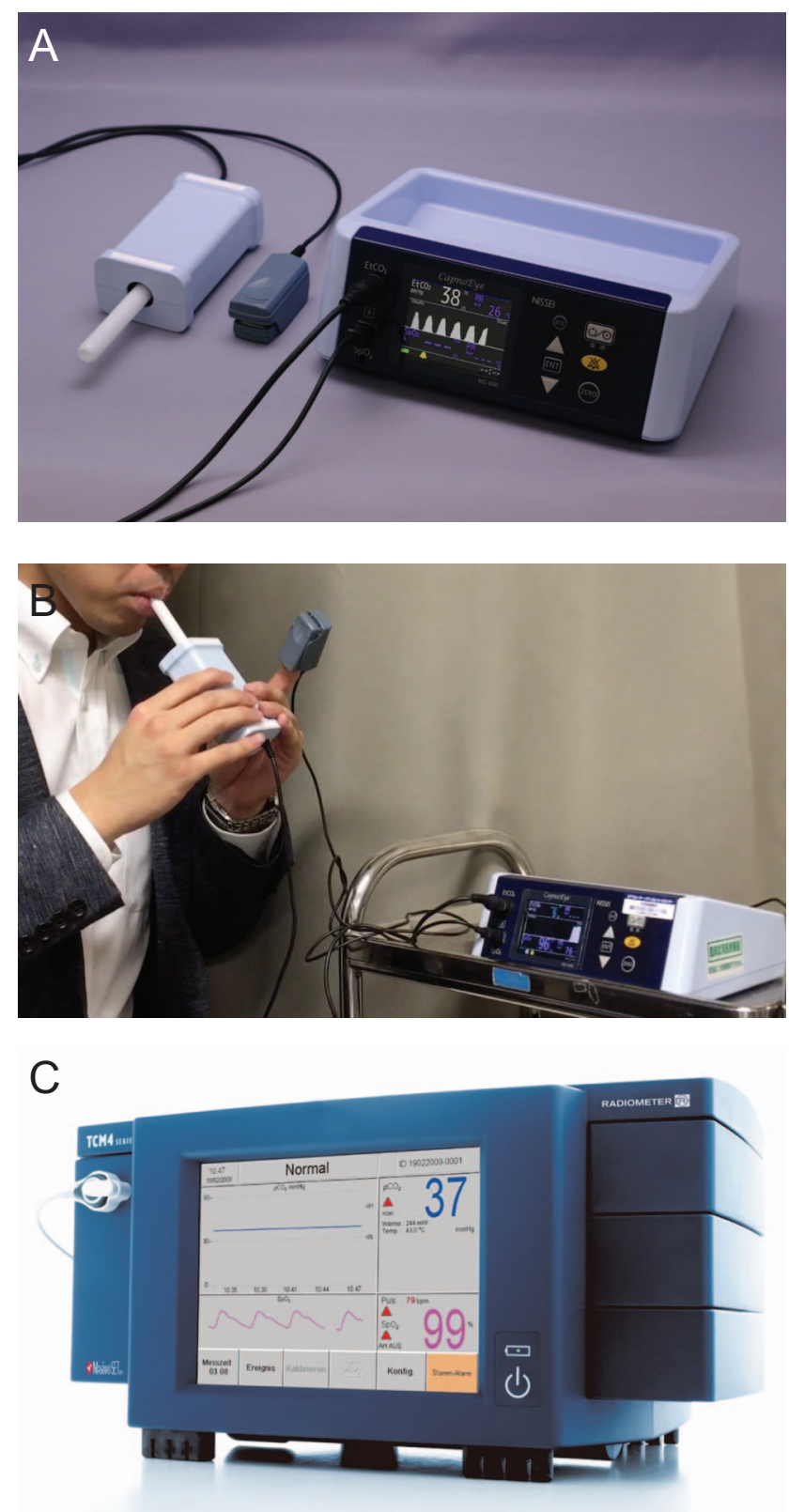

Fig. 1. Equipment used in this study. A: CapnoEye MC-600. B: Measurement of $\mathrm{P}_{\mathrm{ETCO}}$ using CapnoEye MC-600. C: TCM TOSCA. With permission.

rupted immediately before $\mathrm{P}_{\mathrm{ETCO}_{2}}$ measurement to prevent the oxygen flow from affecting the value measured with the capnometer. Oxygen administration was resumed promptly upon completion of the measurement.

\section{Statistical Analysis}

We estimated the required sample size based on data provided by the manufacturer of the capnometer (Air Water Medical); 30 measurements were required for each type of respiratory failure (ie, hypoxemic and hypercarbic).

Data are presented as mean $\pm \mathrm{SD}$. We analyzed the agreements between $\mathrm{P}_{\mathrm{ETCO}_{2}}$ and $\mathrm{P}_{\mathrm{aCO}}$ and between $\mathrm{P}_{\mathrm{tcCO}}$ and $\mathrm{P}_{\mathrm{aCO}}$ with Bland-Altman analysis, and we calculated the estimated bias (ie, the mean difference between 2 methods) and precision (ie, $1 \mathrm{SD}$ of the differences) in subjects with hypoxemic respiratory failure, in subjects with hypercarbic respiratory failure, and in both groups as a whole. Pairwise comparison of characteristics was performed with the Fisher exact test for categorical variables and with the Wilcoxon rank-sum test for non-normally distributed numerical variables. Statistical analysis was performed using JMP 13 (SAS Institute, Cary, North Carolina).

\section{Results}

\section{Subject Characteristics}

Subjects' main characteristics are shown in Table 1; 30 subjects with hypoxemic respiratory failure and 18 subjects with hypercarbic respiratory failure participated in this study. We collected a total of 60 samples (ie, 30 samples from subjects with hypoxemic respiratory failure and 30 samples from subjects with hypercarbic respiratory failure) to confirm the accuracy of the examination in subjects with either high or low carbon dioxide measurements. Some subjects with hypercarbic respiratory failure therefore underwent more than one measurement. The mean age of the subjects was $76 \pm 11$ years. The subjects had various underlying diseases, of which COPD was the most common. Thoracic deformity tended to be more common in subjects with hypercarbic respiratory failure.

\section{Relationships Among Respiratory Function Measures in All Subjects}

Agreements between $\mathrm{P}_{\mathrm{ETCO}_{2}}$ and $\mathrm{P}_{\mathrm{aCO}}$, between $\mathrm{P}_{\mathrm{tcCO}}$ and $\mathrm{P}_{\mathrm{aCO}}$, and between $\mathrm{P}_{\overline{\mathrm{v}} \mathrm{CO}_{2}}$ and $\mathrm{P}_{\mathrm{aCO}_{2}}$ in all subjects are shown in Figure 2. Bland-Altman analysis between $\mathrm{P}_{\mathrm{ETCO}_{2}}$ and $\mathrm{P}_{\mathrm{aCO}}$ revealed a bias of $6.48 \mathrm{~mm} \mathrm{Hg}(95 \% \mathrm{CI}, 4.93-$ $8.03, P \stackrel{P}{<} .001)$ with a precision of $6.01 \mathrm{~mm} \mathrm{Hg}$. BlandAltman analysis between $\mathrm{P}_{\mathrm{tcCO}_{2}}$ and $\mathrm{P}_{\mathrm{aCO}}$ revealed a bias of $1.25 \mathrm{~mm} \mathrm{Hg}(95 \% \mathrm{CI},-0.12$ to $2.63, P=.037)$ with a precision of $5.35 \mathrm{~mm} \mathrm{Hg}$. Bland-Altman analysis between $\mathrm{P}_{\overline{\mathrm{v} C O}}$ and $\mathrm{P}_{\mathrm{aCO}_{2}}$ revealed a bias of $-7.08 \mathrm{~mm} \mathrm{Hg}$ $(95 \% \mathrm{CI},-9.18$ to $-4.97, P<.001)$ with a precision of $8.14 \mathrm{~mm} \mathrm{Hg}$.

\section{Relationships Among Respiratory Function Measures in Subjects With Hypoxemic Respiratory Failure}

Bland-Altman analysis between $\mathrm{P}_{\mathrm{ETCO}_{2}}$ and $\mathrm{P}_{\mathrm{aCO}}$ in subjects with hypoxemic respiratory failure revealed a bias 


\section{$\mathrm{P}_{\mathrm{ETCO}_{2}}$ IN Subjects With Respiratory Failure}

Table 1. Subject Characteristics

\begin{tabular}{|c|c|c|c|c|}
\hline & Subjects & Hypoxemic Respiratory Failure & Hypercarbic Respiratory Failure & $P$ \\
\hline Male gender & $41(68)$ & $25(83)$ & $16(53)$ & .03 \\
\hline Age, y & $76 \pm 11$ & $75 \pm 11$ & $78 \pm 10$ & .29 \\
\hline $\mathrm{P}_{\mathrm{aCO}_{2}}, \mathrm{~mm} \mathrm{Hg}$ & $48 \pm 13$ & $39 \pm 5$ & $56 \pm 10$ & $<.001$ \\
\hline $\mathrm{P}_{\overline{\mathrm{v} C O}_{2}}, \mathrm{~mm} \mathrm{Hg}$ & $55 \pm 14$ & $46 \pm 6$ & $63 \pm 14$ & $<.001$ \\
\hline $\mathrm{P}_{\mathrm{ETCO}_{2}}, \mathrm{~mm} \mathrm{Hg}$ & $41 \pm 11$ & $33 \pm 5$ & $49 \pm 8$ & $<.001$ \\
\hline $\mathrm{P}_{\mathrm{tcCO}_{2}}, \mathrm{~mm} \mathrm{Hg}$ & $47 \pm 12$ & $38 \pm 5$ & $55 \pm 9$ & $<.001$ \\
\hline COPD & $29(48)$ & $16(53)$ & $13(43)$ & .61 \\
\hline Interstitial pneumonia & $15(25)$ & $10(33)$ & $5(16)$ & .23 \\
\hline Previous tuberculosis & $13(22)$ & $6(20)$ & $7(23)$ & $>.99$ \\
\hline Bronchiectasis & $4(7)$ & $2(7)$ & $2(7)$ & $>.99$ \\
\hline Asthma & $13(22)$ & $5(17)$ & $8(27)$ & .53 \\
\hline Lung cancer & $4(7)$ & $3(10)$ & $1(3)$ & .61 \\
\hline Thoracic deformity & $11(18)$ & $2(7)$ & $9(30)$ & .041 \\
\hline Pneumonia & $11(18)$ & $5(17)$ & $6(20)$ & $>.99$ \\
\hline Chronic pulmonary aspergillosis & $1(2)$ & $1(3)$ & $0(0)$ & $>.99$ \\
\hline Non-tuberculous mycobacterium & $2(4)$ & $0(0)$ & $2(7)$ & .49 \\
\hline Pulmonary thromboembolism & $2(3)$ & $2(7)$ & $0(0)$ & .49 \\
\hline Chronic heart failure & $9(15)$ & $4(13)$ & $5(17)$ & $>.99$ \\
\hline \multicolumn{5}{|c|}{$\begin{array}{l}\text { There were } 60 \text { total samples, } 30 \text { samples from each respiratory failure group. Data are presented as mean } \pm \mathrm{SD} \text { or } n(\%) \text {. If a subject had multiple diseases, we counted each disease as a separate } \\
\text { case. The Fisher exact test was used for categorical variables, and the Wilcoxon rank-sum was used for numerical variables. } \\
\mathrm{P}_{\overline{\mathrm{v}} \mathrm{CO}_{2}}=\text { mixed venous partial pressure of carbon dioxide } \\
\mathrm{P}_{\mathrm{tcCO}}=\text { transcutaneously measured partial pressure of carbon dioxide }\end{array}$} \\
\hline
\end{tabular}

of $5.14 \mathrm{~mm} \mathrm{Hg}(95 \% \mathrm{CI}, 3.35-6.93, P<.001)$ with a precision of $4.80 \mathrm{~mm} \mathrm{Hg}$. Bland-Altman analysis between $\mathrm{P}_{\mathrm{tcCO}_{2}}$ and $\mathrm{P}_{\mathrm{aCO}_{2}}$ revealed a bias of $0.97 \mathrm{~mm} \mathrm{Hg}$ $(95 \% \mathrm{CI},-0.59$ to $2.54, P=.10)$ with a precision of $4.19 \mathrm{~mm} \mathrm{Hg}$. Bland-Altman analysis between $\mathrm{P}_{\overline{\mathrm{v}} \mathrm{CO}_{2}}$ and $\mathrm{P}_{\mathrm{aCO}}$ revealed a bias of $-7.79 \mathrm{~mm} \mathrm{Hg}(95 \% \mathrm{CI}-9.80$ to $-5.77, P<.001$ ) with a precision of $5.51 \mathrm{~mm} \mathrm{Hg}$.

\section{Relationships Among Respiratory Function Measures in Subjects With Hypercarbic Respiratory Failure}

Bland-Altman analysis between $\mathrm{P}_{\mathrm{ETCO}_{2}}$ and $\mathrm{P}_{\mathrm{aCO}_{2}}$ in subjects with hypercarbic respiratory failure revealed a bias of $7.83 \mathrm{~mm} \mathrm{Hg}(95 \%$ CI $5.27-10.38, P<.001)$ with a precision of $6.83 \mathrm{~mm} \mathrm{Hg}$. Bland-Altman analysis between $\mathrm{P}_{\mathrm{tcCO}}$ and $\mathrm{P}_{\mathrm{aCO}}$ revealed a bias of $1.53 \mathrm{~mm} \mathrm{Hg}$ (95\% CI -0.84 to $3.90, P=.09$ ) with a precision of $6.36 \mathrm{~mm} \mathrm{Hg}$. Bland-Altman analysis between $\mathrm{P}_{\overline{\mathrm{v}} \mathrm{CO}_{2}}$ and $\mathrm{P}_{\mathrm{aCO}_{2}}$ revealed a bias of $-6.37 \mathrm{~mm} \mathrm{Hg}(95 \% \mathrm{CI},-10.0$ to $-2.65, P<.001$ ) with a precision of $10.2 \mathrm{~mm} \mathrm{Hg}$.

\section{Discussion}

Our findings showed that simple and noninvasive measurements of $\mathrm{P}_{\mathrm{ETCO}}$ with a capnometer estimated $\mathrm{P}_{\mathrm{aCO}}$. However, the limits of agreement were wide. Therefore, care providers must pay attention to the characteristics and errors of these devices.
$\mathrm{P}_{\mathrm{ETCO}_{2}}$ is often measured in closed circuits in patients undergoing mechanical ventilation. In the absence of significant changes in cardiac output or the ventilation/perfusion ratio, $\mathrm{P}_{\mathrm{aCO}_{2}}$ can then be estimated with clinically acceptable sensitivity and specificity in comparison with $\mathrm{P}_{\mathrm{ETCO}_{2}}{ }^{5,6}$ However, accurate measurement of $\mathrm{P}_{\mathrm{ETCO}_{2}}$ has been problematic in patients who are not intubated because it is difficult to collect pure respiratory gas. Several recently developed transportable capnometers can measure $\mathrm{P}_{\mathrm{ETCO}_{2}}$ easily and noninvasively in patients who are not intubated, and a recent study showed that they could provide reliable $\mathrm{P}_{\text {ETCO }}$ values compared with $\mathrm{P}_{\mathrm{aCO}}{ }_{2}{ }^{7}$ We therefore examined the usefulness of this approach in terms of the principle, experience of use, and measured values. A previous study showed that $\mathrm{P}_{\mathrm{ETCO}_{2}}$ was $2-5 \mathrm{~mm} \mathrm{Hg}$ lower than $\mathrm{P}_{\mathrm{aCO}_{2}}$ during general anesthesia in subjects without lung disease, ${ }^{8}$ and we observed that $\mathrm{P}_{\mathrm{ETCO}_{2}}$ was $6 \pm 6 \mathrm{~mm} \mathrm{Hg}$ lower than $\mathrm{P}_{\mathrm{aCO}}$. This study revealed wide limits of agreement in each group, which suggests that the measurement of $\mathrm{P}_{\mathrm{ETCO}_{2}}$ with a capnometer requires attention to the characteristics and errors of these devices.

$\mathrm{P}_{\mathrm{tcCO}_{2}}$ is more accurate than other measurements in any patient group. However, $\mathrm{P}_{\mathrm{tcCO}}$ is complicated to measure and the required equipment is expensive, and therefore this technique is less widely used than pulse oximetry. There is thus a need to develop devices that can easily estimate $\mathrm{P}_{\mathrm{aCO}}$. 


\section{$\mathrm{P}_{\mathrm{ETCO}_{2}}$ IN SubJects With Respiratory Failure}
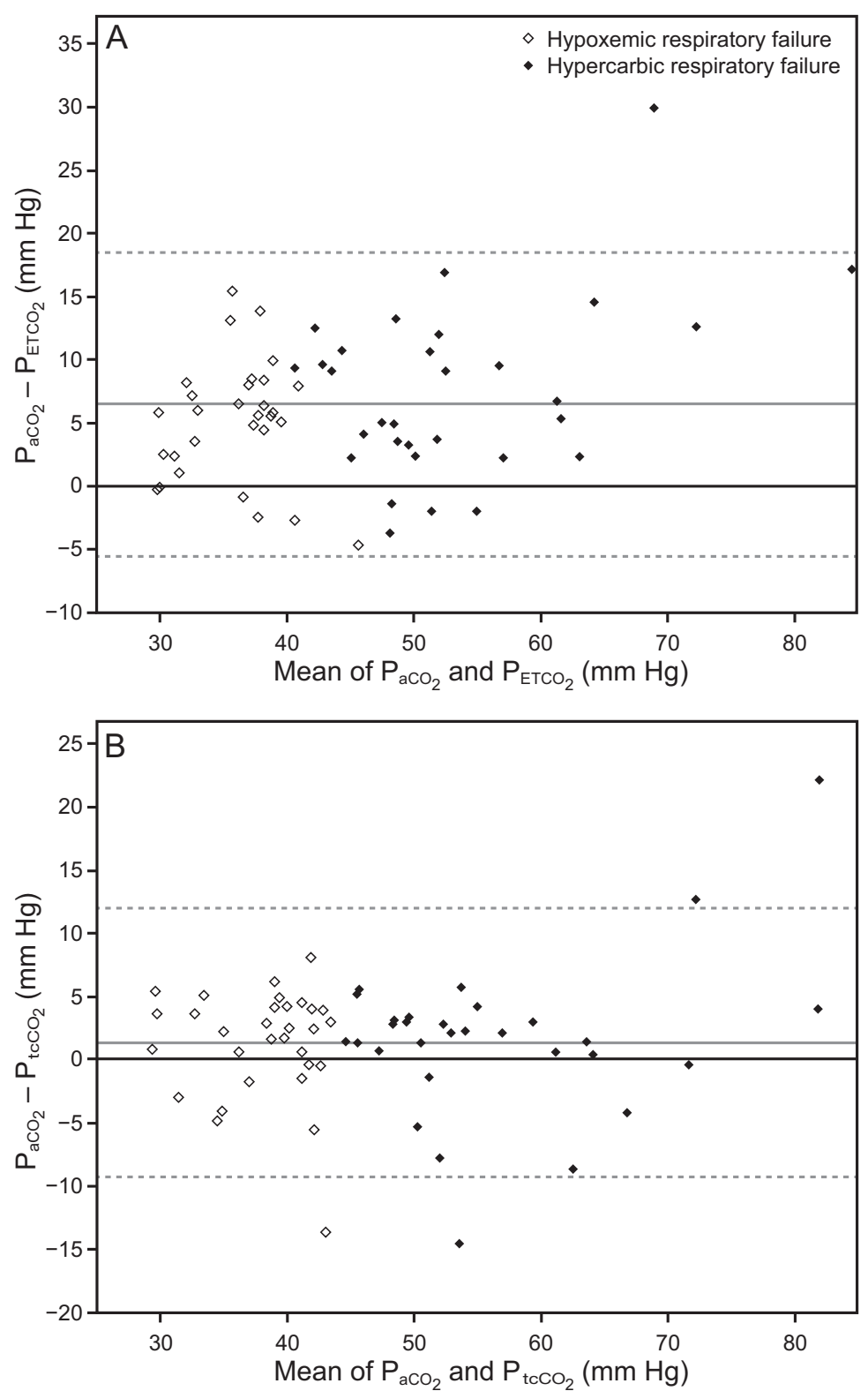

Fig. 2. Bland-Altman analysis of respiratory gas parameters in all subjects. A: Comparison of $\mathrm{P}_{\mathrm{ETCO}}$ and $\mathrm{P}_{\mathrm{acO}}$ in all subjects, with mean bias and limits of agreement. The solid line indicates bias $=6.48$; dotted lines indicate upper and lower limits of agreement $( \pm 1.96 \mathrm{SD})$. $\mathrm{B}$ : Comparison of $\mathrm{P}_{\mathrm{tcCO}}$ and $\mathrm{P}_{\mathrm{acO}}$ in all subjects, with mean bias and limits of agreement. The solid line indicates bias = 1.25; dotted lines indicate upper and lower limits of agreement $( \pm 1.96 \mathrm{SD})$.

A previous study reported that $\mathrm{P}_{\mathrm{aCO}_{2}}$ measurements at the time of COPD exacerbation could be replaced with $\mathrm{P}_{\overline{\mathrm{v}} \mathrm{CO}_{2}}$ measurements. ${ }^{9}$ However, although $\mathrm{P}_{\overline{\mathrm{v}} \mathrm{CO}_{2}}$ may be a useful measure, venous blood sampling is mildly invasive. Our results indicate that $\mathrm{P}_{\mathrm{ETCO}}$ agreed with $\mathrm{P}_{\mathrm{aCO}}$ as well as or better than $\mathrm{P}_{\overline{\mathrm{v} C O}}$ in any subject group, suggesting that $\mathrm{P}_{\mathrm{ETCO}_{2}}$ may be a more useful measure than $\mathrm{P}_{\overline{\mathrm{v}} \mathrm{CO}_{2}}$.

The relative advantages and disadvantages of the capnometer and the transcutaneous carbon dioxide monitor are shown in Table 2. The capnometer is small and easy to carry, allowing it to be used regardless of location. In addition, measurements can be performed within a few minutes, allowing its use even during out-patient clinical practice. It can also be used in settings outside of the hospital or out-patient clinic where blood gas analysis is not an option, such as during house calls. We observed no measurement-related complications in this study, and the patient burden was very small. Furthermore, the only equipment required is disposable mouthpieces, allowing the capnometer to measure $\mathrm{P}_{\mathrm{ETCO}}$ at low cost. The capnometer has a disadvantage, however, in that the measured value changes depending on the patient's breathing pattern, and 


\section{$\mathrm{P}_{\mathrm{ETCO}_{2}}$ IN Subjects With Respiratory Failure}

Table 2. Advantages and Disadvantages of CapnoEye and TCM TOSCA

\begin{tabular}{lll}
\hline \hline & \multicolumn{1}{c}{ CapnoEye } & \multicolumn{1}{c}{ TCM TOSCA } \\
\hline Advantages & $\bullet$ Easy to use & $\bullet$ More precise value \\
& $\bullet$ Portable & $\bullet$ Objective value \\
& $\bullet$ Inexpensive & $\bullet$ Can be usure continuously for unconscious patients \\
& $\bullet$ Can measure in a few minutes & $\bullet$ Can record \\
& $\bullet$ Can be used in primary care & $\bullet$ Complicated to use \\
& $\bullet$ No complications in measurement & $\bullet$ Expensive \\
& $\bullet$ Measurement values depend on the breathing & $\bullet$ Need a long time to measure \\
Disadvantages & $\bullet$ pattern and oxygen flow & $\bullet$ Complications of low-temperature burns \\
& $\bullet$ Can't measure continuously & \\
\hline
\end{tabular}

measured values of inhaled oxygen may be affected by oxygen flow. The developer of the device states that supplemental $\mathrm{O}_{2}$ does not significantly affect the examination value at a flow $\leq 2 \mathrm{~L}$ of nasal oxygen. However, administration must be interrupted in cases of higher oxygen flows. In our study, we interrupted oxygen delivery at the time of measurement, and we therefore did not consider the relationship between oxygen flow and the measured value. Further studies are needed to clarify the effect of oxygen administration.

Another disadvantage of the capnometer is its inability to continuously monitor and record measurement values inside the equipment. Transcutaneous carbon dioxide monitors provide such measurements, and our results indicate that $\mathrm{P}_{\mathrm{tcCO}_{2}}$ is more accurate than $\mathrm{P}_{\mathrm{ETCO}_{2}}$. Transcutaneous carbon dioxide monitors also measure $\mathrm{P}_{\mathrm{tcCO}}$ continuously, and they can be used in patients with altered mental status, making them useful in ICUs and operating rooms. However, the measurement method is complicated and lengthy, and errors are caused by mixing of air. Furthermore, lowtemperature burns have also been reported, ${ }^{11}$ and the device must therefore be moved periodically to avoid this complication. This technique is limited further by the relative expense of the equipment and accessories. In addition, measurements obtained with transcutaneous carbon dioxide monitors tend to be higher than the $\mathrm{P}_{\mathrm{aCO}}$ when the measured value is $\geq 50 \mathrm{~mm} \mathrm{Hg} .{ }^{4}$ We confirmed that measurement of $\mathrm{P}_{\mathrm{ETCO}_{2}}$ with a capnometer could provide a simpler approach than measurement of $\mathrm{P}_{\mathrm{tcCO}}$.

This study had several limitations. First, the capnometer measurement depends on the subject's breathing pattern, thus the examiner must be familiar with the measurement method. Furthermore, caution is needed because expired air may leak from the corners of the patient's nose and mouth. Although $\mathrm{P}_{\mathrm{ETCO}}$ was measured only once in this study, it may be possible to reduce error by measuring $\mathrm{P}_{\mathrm{ETCO}_{2}}$ several times and using the average value. Second, numerous factors reportedly weaken the correlation be- tween $\mathrm{P}_{\mathrm{ETCO}_{2}}$ and $\mathrm{P}_{\mathrm{aCO}}$ in mechanically ventilated patients, ${ }^{11,12}$ including severe respiratory failure, obesity, pregnancy, breathing frequency at the time of measurement, and posture, ${ }^{13-15}$ and these factors should also be taken into consideration when measuring $\mathrm{P}_{\mathrm{ETCO}}$ with a capnometer. Third, some patients with hypercarbic respiratory failure underwent repeated measurements, which may be a source of bias. Finally, although we drew from either the right or left antecubital vein and took the tourniquet time as the minimum necessary time, we attempted to reduce the bias as much as possible by having the same researcher draw blood in the same way for all samples. In contrast, $\mathrm{P}_{\overline{\mathrm{v}} \mathrm{CO}_{2}}$ is affected by local conditions, such as muscle conditions, and does not represent the partial pressure of central venous carbon dioxide, which may partly explain why $\mathrm{P}_{\overline{\mathrm{v}} \mathrm{CO}_{2}}$ had a poor agreement with $\mathrm{P}_{\mathrm{aCO}} \cdot \mathrm{P}_{\mathrm{ETCO}_{2}}$ and $\mathrm{P}_{\mathrm{tcCO}_{2}}$ have shown agreements with $\mathrm{P}_{\mathrm{aCO}}$ commensurate with the increasing accuracy of the measuring instruments, and these measurements have become clinically applied as a substitute for $\mathrm{P}_{\mathrm{aCO}}$. However, caution is required for its application, and use without knowing the advantages and disadvantages of this method may result in erroneous results and improper clinical interpretation. Further studies are needed to assess their suitability in different diseases and clinical situations.

\section{Conclusions}

In this study, $\mathrm{P}_{\mathrm{ETCO}_{2}}$ can be measured simply and noninvasively with a capnometer, and $\mathrm{P}_{\mathrm{ETCO}_{2}}$ measurements can estimate $\mathrm{P}_{\mathrm{aCO}}$. However, the limits of agreement were wide. Therefore, care providers must pay attention to the characteristics and potential errors of these devices. Our results suggest that measurement of $\mathrm{P}_{\mathrm{ETCO}_{2}}$ might be useful for screening for hypercarbic respiratory failure in the clinical setting, although further studies are needed to confirm the usefulness of these measurements. 


\section{$\mathrm{P}_{\mathrm{ETCO}_{2}}$ IN SubJects With Respiratory Failure}

\section{ACKNOWLEDGMENTS}

We are grateful to the study members and their friends and families for their continued support. We are also grateful to Dr Noriko Tanaka and the medical research coordinators and laboratory technicians at National Center for Global Health and Medicine for their assistance with data analysis and management. Finally, we thank Angela Morben DVM ELS and Susan Furness PhD, from Edanz Group, for editing a draft of this manuscript.

\section{REFERENCES}

1. McArthur CD, American Association for Respiratory Care. AARC clinical practice guideline. Capnography/capnometry during mechanical ventilation-2003 revision \& update. Respir Care 2003;48(5): 534-539.

2. Kodali BS. Capnography outside the operating rooms. Anesthesiology 2013;118(1):192-201.

3. Simon M, Gottschall R, Gugel M, Fritz H, Mohr S, Klein U. Comparison of transcutaneous and endotidal $\mathrm{CO}_{2}$-monitoring for rigid bronchoscopy during high-frequency jet ventilation. Acta Anaesthesiol Scand 2003;47(7):861-867.

4. Eberhard P, Gisiger PA, Gardaz JP, Spahn DR. Combining transcutaneous blood gas measurement and pulse oximetry. Anesth Analg 2002;94(1 Suppl):S76-S80.

5. Anderson CT, Breen PH. Carbon dioxide kinetics and capnography during critical care. Crit Care 2000;4(4):207-215.

6. Morley TF, Giaimo J, Maroszan E, Bermingham J, Gordon R, Griesback R, et al. Use of capnography for assessment of the adequacy of alveolar ventilation during weaning from mechanical ventilation. Am Rev Respir Dis 1993;148(2):339-344.

7. Kyung WK, Hey RC, Si RB, Jeong WL. Comparison of end-tidal $\mathrm{CO}_{2}$ measured by transportable capnometer (EMMA ${ }^{\mathrm{TM}}$ capnograph) and arterial $\mathrm{pCO}_{2}$ in general anesthesia. J Clin Monit Comput 2015; 30(5):737-741.

8. Hess D. Capnometry. In: Tobin MJ. Principles and practice of intensive care monitoring. New York: McGraw-Hill; 1997:377-400.

9. McKeever TK, Hearson G, Housley G, Reynolds C, Kinnear W, Harrison TW, et al. Using venous blood gas analysis in the assessment of COPD exacerbations: a prospective cohort study. Thorax 2016;71(3):210-215.

10. Dullenkopf A, DiBernardo S, Berger F, Fasnacht M, Gerber AC, Weiss M. Evaluation of a new combined $\mathrm{S}_{\mathrm{pO}_{2}} / \mathrm{P}_{\mathrm{tcCO}_{2}}$ sensor in anaesthetized paediatric patients. Paediatr Anaesth 2003;13(9):777-784.

11. Cheifetz IM, Myers TR. Should every mechanically ventilated patient be monitored with capnography from intubation to extubation? Respir Care 2007;52(4):423-442.

12. Wahba RW, Tessler MJ. Misleading end-tidal $\mathrm{CO}_{2}$ tensions. Can J Anaesth 1996;43(8):862-866.

13. Szaflarski NL, Cohen NH. Use of capnography in critically ill adults. Heart Lung 1991;20(6):363-372.

14. Shankar KB, Moseley H, Kumar Y, Vemula V. Arterial to end tidal carbon dioxide tension difference during caesarean section anaesthesia. Anaesthesia 1986;41(7):698-702.

15. Grenier B, Verchere E, Mesli A, Dubreuil M, Siao D, Vandendriessche $\mathrm{M}$, et al. Capnography monitoring during neurosurgery: reliability in relation to various intraoperative positions. Anesth Analg 1999;88(1):43-48.

This article is approved for Continuing Respiratory Care Education credit. For information and to obtain your CRCE

(free to AARC members) visit

www.rcjournal.com

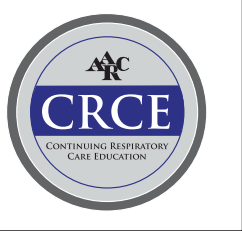

